Kasuistik / Casuistry

\title{
Stellungnahmen und Erwiderungen zu der Arbeit / Comments and Remarks on
}

Experiments on the Penetration Power

of Various Bullets into Skin and Muscle Tissue

D. Tausch, W. Sattler, K. Wehrfritz, G. Wehrfritz, and H.-J. Wagner

Z. Rechtsmed. 81, 309-328 (1978)

Key words: Penetration power, of spherical or ogival projectiles - Projectile velocities - Shot, penetration power of bullets

Schlüsselwörter: Schuß, Geschoßgeschwindigkeit - Geschoßgeschwindigkeiten

- Durchschlagskraft, bei verschiedenartigen Projektilen

In Anbetracht der wissenschaftlichen und praktischen Bedeutung der o. a. Arbeit hält es die Schriftleitung für notwendig, eine Stellungnahme von W. Dammermann, Braunschweig, und eine Erwiderung von D. Tausch, W. Sattler, K. Wehrfritz, G. Wehrfritz und H.-J. Wagner, Homburg/Saar, abzudrucken. Die Schriftleitung hat zusätzlich eine Stellungnahme von K. Sellier, Bonn, erbeten, die ebenfalls zum Abdruck gebracht wird.

Die Schriftleitung 